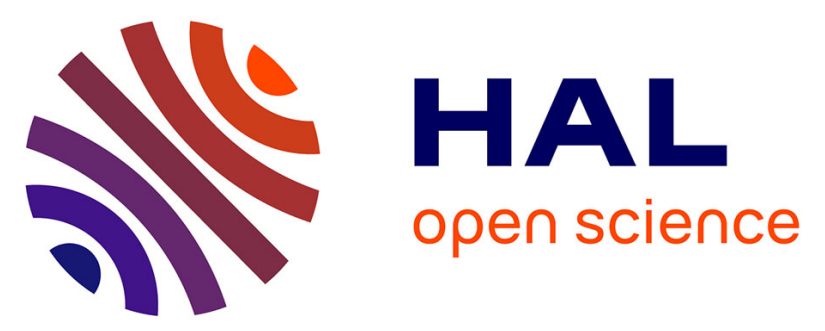

\title{
The Random Neural Network with a Genetic Algorithm and Deep Learning Clusters in Fintech: Smart Investment
}

Will Serrano

\section{- To cite this version:}

Will Serrano. The Random Neural Network with a Genetic Algorithm and Deep Learning Clusters in Fintech: Smart Investment. 14th IFIP International Conference on Artificial Intelligence Applications and Innovations (AIAI), May 2018, Rhodes, Greece. pp.297-310, 10.1007/978-3-319-92007-8_26 . hal-01821045

\section{HAL Id: hal-01821045 \\ https://hal.inria.fr/hal-01821045}

Submitted on 22 Jun 2018

HAL is a multi-disciplinary open access archive for the deposit and dissemination of scientific research documents, whether they are published or not. The documents may come from teaching and research institutions in France or abroad, or from public or private research centers.
L'archive ouverte pluridisciplinaire HAL, est destinée au dépôt et à la diffusion de documents scientifiques de niveau recherche, publiés ou non, émanant des établissements d'enseignement et de recherche français ou étrangers, des laboratoires publics ou privés.

\section{(c)(1)}

Distributed under a Creative Commons Attribution| 4.0 International License 


\title{
The Random Neural Network with a Genetic Algorithm \& Deep Learning Clusters in Fintech: Smart Investment
}

\author{
Will Serrano \\ Intelligent Systems and Networks Group \\ Electrical and Electronic Engineering \\ Imperial College London \\ g.serranol1@imperial.ac.uk
}

\begin{abstract}
This paper presents the Random Neural Network in a Deep Learning Cluster structure with a new learning algorithm based on the genetics according to the genome model, where information is transmitted in the combination of genes rather than the genes themselves. The proposed genetic model transmits information to future generations in the network weights rather than the neurons. The innovative genetic algorithm is implanted in a complex deep learning structure that emulates the human brain: Reinforcement Learning takes fast local current decisions, Deep Learning Clusters provide identity and memory, Deep Learning Management Clusters take final strategic decisions and finally Genetic Learning transmits the information learned to future generations. This proposed structure has been applied and validated in Fintech; a Smart Investment application: an Intelligent Banker that performs Buy and Sell decisions on several Assets with an associated market and risk. Our results are promising; we have connected the human brain and genetics with Machine Learning based on the Random Neural Network model where biology; similar as Artificial Intelligence is learning gradually and continuously while adapting to the environment.
\end{abstract}

Keywords: Genetic Learning, Deep Learning Clusters, Reinforcement Learning, Random Neural Network, Smart Investment; Fintech.

\section{$1 \quad$ Introduction}

Biology is gradually and continuously learning while adapting to the environment using genetic changes to generate new complex structures in organisms [1], the current structure of the organisms defines the type and level of future genetic variation that will provide a better adaption to the environment or increased reward to a goal function. Random genetic changes have more probability to be successful in organisms that change in a systematic and modular manner where the new structures acquire the same set of sub goals in different combinations; therefore they not only remember their reward evolution but also generalize goal functions to successfully 
adapt future environments [2]. The adaptations learned from the living organisms affect and guide evolution even though the characteristics acquired are not transmitted to the genome [3], however, its gene functions are altered and transmitted to the new generation; this enables learning organisms to evolve much faster.

The genome is the genetic material of an organism; it consists of 23 pairs of chromosomes (1-22, X and Y) for a human cell formed of genes (approximately 21,000 in total) that code for a molecule that has a function or instruction to make proteins [4], furthermore genes are formed of base pairs (approximately 3 billion in total). The DNA is a double helix formed by the combination of only four nucleotides (cytosine $[\mathrm{C}]$, guanine $[\mathrm{G}]$, adenine $[\mathrm{A}]$ or thymine $[\mathrm{T}]$ ) where each base pair consists of the combination of two nucleoids G-C and A-T. The genetic code is formed of codons, a sequence consisted of three nucleotides or three-letter words. Proteins that have similar combination of base pairs tend to have a related functionality determination of protein functions from genetic sequences [5].

Successful Machine Learning and Artificial Intelligence models have been purely based on biology emulating the structures provided by nature during the learning, adaptation and evolution when interacting with the external environment. Neural networks and deep learning are based on the brain structure which is formed of dense local clusters of same neurons performing different functions which are connected between each other with numerous very short paths and few long distance connections [6]. The brain retrieves a large amount of data obtained from the senses; analyses the material and finally selects the relevant information [7] where the cluster of neurons specialization occurs due to their adaption when learning tasks.

This paper proposes a new genetic learning algorithm on Section 3 based on the genome and evolution; where the information transmitted to new generations is learned when interacting and adapting to the environment using reinforcement and deep learning respectively. Information in the proposed genetic algorithm is transmitted in the network weights through the different combinations of four different nodes $(\mathrm{C}, \mathrm{G}, \mathrm{A}, \mathrm{T})$ rather than the value of nodes themselves where the output layer of nodes replicates the input layer as the genome. This innovative genetic algorithm is inserted in a complex deep learning structure that emulates the human brain on Section 4: Reinforcement Learning takes fast local current decisions, Deep Learning clusters provide identity and memory, Deep Learning Management Clusters takes final strategic decisions and finally Genetic Learning transmits the information learned to future generations. This innovative model has been applied and validated in Fintech, a Smart Investment application on Section 5; an Intelligent Banker that performs Buy and Sell decisions on several assets with an associated market and risk. The results shown on Section 6 are promising; the Intelligent Banker takes the right decisions, learns the variable asset price, makes profits on specific markets at minimum risk and finally it transmits the information learned to future generations. 


\section{Related work}

Artificial Neural Networks have been applied to make financial predictions. Leshno, M. et al [8] evaluate the bankruptcy prediction capability of several neural network models based on the firm's financial reports. Chen, W. et al [9] uses Artificial Neural Networks for a financial distress prediction model. Kara, Y. et al [10] apply an Artificial Neural Network to predict the direction of Stock Market index movement. Guresen, E. [11] evaluates the effectiveness of neural network models in stock market predictions. Zhang, G. et al [12] analyse Artificial Neural Networks in bankruptcy prediction. Kohara, K. et al [13] investigate different ways to use prior knowledge and neural networks to improve multivariate prediction ability. Sheta, A. et al [14] compares Regression, Artificial Neural Networks and Support Vector Machines for predicting the S\&P 500 Stock Market Price Index. Tung, T. et al [15] includes Artificial Neural Networks and Fuzzy Logic for market predictions. Pakdaman, M. et al [16] use a feedforward multilayer perceptron and an Elman recurrent Network to predict a company's stock value. Iuhasz, G. et al [17] create a hybrid system based on a multi Agent Architecture to analyse Stock Market behaviour to improve the profitability in a short or medium time period investment. Nicholas, A. et al [18] examine the use of neural networks in stock performance modelling.

Several survey papers haven been published. Bahrammirzaee, A. [19] presents a comparative survey of Artificial Intelligence Applications in Finance: Artificial Neural Networks, Expert System and hybrid intelligent systems. Coakley, J. et al [20] reviews the use of Artificial Neural Networks in Accounting and Finance including modeling issues and guidelines. Fadlalla, A et al [21] analyses the applications of Neural Networks in Finance. Huang, W. et al [22] reviews the use of neural networks in finance and economics forecasting. Li, Y. et al [23] summarize different applications or artificial intelligence technologies in several domains of business administration including finance, retail, manufacturing and management consultancy.

Machine learning has been applied to solve nonlinear models in continuous time in economics and finance by Duarte, V. [24] and forecasting the volatility of asset prices by Stefani, J. et al [25]. Deep Learning has also recently incorporated in long short term memory Neural Networks for financial market predictions by Fischer, T. et al [26] and Hasan, A. et al [27].

Genetic Algorithms have been proposed as method to increase learning. Arifovic, J. [28] analyses genetic algorithms in inflationary economies. Kim, K. et al [29] uses a genetic Algorithm to feature discretization in artificial neural networks for the prediction of stock market index. Ticona, W. et al [30] applies a hybrid model based on Genetic algorithm and Neural Networks to forecast Tax Collection. Hossain, D. et al [31] present a Genetic Algorithm based Deep Learning Method. Sremath, S. [32] and David, O. et al [33] review of the latest deep learning structures and evolutionary algorithms that can be used to train them. 


\section{The Random Neural Network Genetic Deep Learning Model}

\subsection{The Random Neural Network}

The RNN [34-36] represents more closely how signals are transmitted in many biological neural networks where they travel as spikes or impulses, rather than as analogue signal levels. The RNN is a spiking recurrent stochastic model for neural networks. Its main analytical properties are the "product form" and the existence of the unique network steady state solution. The Random Neural network has been Genetics [37-46].

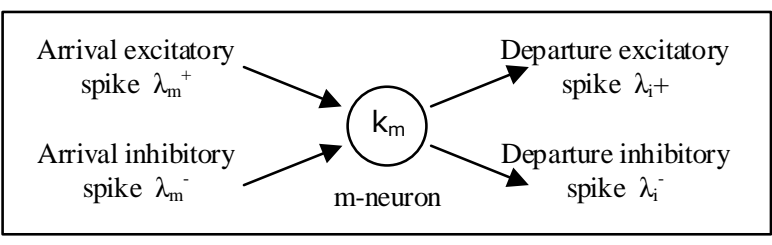

Fig. 1. The Random Neural Network

\subsection{The Random Neural Network with Multiple clusters}

Deep Learning with Random Neural Networks is described by Gelenbe, E. and Yin, Y. [47-49]. This model is based on the generalized queuing networks with triggered customer movement (G-networks) where customers are either "positive" or "negative" and customers can be moved from queues or leave the network. G-Networks are introduced by Gelenbe, E. [50, 51]; an extension to this model is developed by Gelenbe, E. et al [52] where synchronised interactions of two queues could add a customer in a third queue.

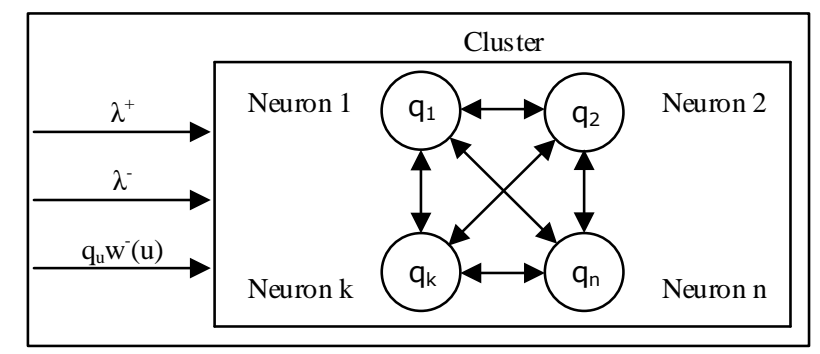

Fig. 2. Clusters of Neurons

\subsection{Deep Learning management cluster}

The Deep Learning management cluster was proposed by Serrano, W et al [53-56]. It takes management decisions based on the inputs from different Deep Learning clusters. 


\subsection{Genetic Learning Algorithm model}

The proposed Genetic learning algorithm is based on the auto encoder presented by Gelenbe, E. and Yin, Y. [47-49] based on two instances of the Network shown on Figure 3, the auto encoder models the genome as it codes the replica of the organism that contains it. Network 1 is formed of $\mathrm{U}$ input neurons and C clusters and Network 2 has $\mathrm{C}$ input neurons and $\mathrm{U}$ clusters. The organism is represented as a set of data $\mathrm{X}$ which is a $U$ vector $X \in[0,1]^{\mathrm{U}}$. The proposed Genetic learning algorithm fixes $\mathrm{C}$ to 4 neurons that represent the four different nucleoids $\mathrm{G}, \mathrm{C}, \mathrm{A}$ and $\mathrm{T}$ and it also fixes $\mathrm{W}_{1}$ to generate 4 different types of neurons rather than random values.

Network 1 encodes the organism, it is defined as:

- $\mathrm{q}_{1}=\left(\mathrm{q}_{1}^{1}, \mathrm{q}_{2}^{1}, \ldots, \mathrm{q}_{\mathrm{u}}^{1}\right)$, a U-dimensional vector $\mathrm{q}_{1} \in[0,1]^{\mathrm{U}}$ that represents the input state $\mathrm{q}_{\mathrm{u}}$ for neuron $\mathrm{u}$;

- $\mathrm{W}_{1}$ is the $\mathrm{U} \times \mathrm{C}$ matrix of weights $\mathrm{w}_{1}{ }^{-}(\mathrm{u}, \mathrm{c})$ from the $\mathrm{U}$ input neurons to the neurons in each of the $\mathrm{C}$ clusters;

- $\mathrm{Q}^{1}=\left(\mathrm{Q}_{1}^{1}, \mathrm{Q}_{2}^{1}, \ldots, \mathrm{Q}_{\mathrm{c}}^{1}\right)$, a $\mathrm{C}$-dimensional vector $\mathrm{Q}^{1} \in[0,1]^{\mathrm{C}}$ that represents state $\mathrm{q}_{\mathrm{c}}$ for the cluster $\mathrm{c}$ where $\mathrm{Q}^{1}=\zeta\left(\mathrm{W}_{1} \mathrm{X}\right)$.

Network 2 decodes the genome, as the pseudo inverse of Network 1, it is defined as:

- $\mathrm{q}_{2}=\left(\mathrm{q}_{1}^{2}, \mathrm{q}_{2}^{2}, \ldots, \mathrm{q}_{\mathrm{c}}^{2}\right)$, a C-dimensional vector $\mathrm{q}_{2} \in[0,1]^{\mathrm{C}}$ that represents the input state $\mathrm{q}_{\mathrm{c}}$ for neuron $\mathrm{c}$ with the same value as $\mathrm{Q}^{1}=\left(\mathrm{Q}_{1}^{1}{ }_{1} \mathrm{Q}^{1}{ }_{2}, \ldots, \mathrm{Q}_{\mathrm{c}}^{1}\right)$;

- $\mathrm{W}_{2}$ is the $\mathrm{C} \times \mathrm{U}$ matrix of weights $\mathrm{w}_{2}{ }^{-}(\mathrm{c}, \mathrm{u})$ from the $\mathrm{C}$ input neurons to the neurons in each of the $\mathrm{U}$ cells;

- $\mathrm{Q}^{2}=\left(\mathrm{q}_{1}^{2}, \mathrm{q}_{2}^{2}, \ldots, \mathrm{q}_{\mathrm{u}}^{2}\right)$, a U-dimensional vector $\mathrm{Q}^{2} \in[0,1]^{\mathrm{U}}$ that represents the state $\mathrm{q}_{\mathrm{u}}$ for the cell $\mathrm{u}$ where $\mathrm{Q}^{2}=\zeta\left(\mathrm{W}_{2} \mathrm{Q}^{1}\right)$ or $\mathrm{Q}^{2}=\zeta\left(\mathrm{W}_{2} \zeta\left(\mathrm{XW}_{1}\right)\right)$.

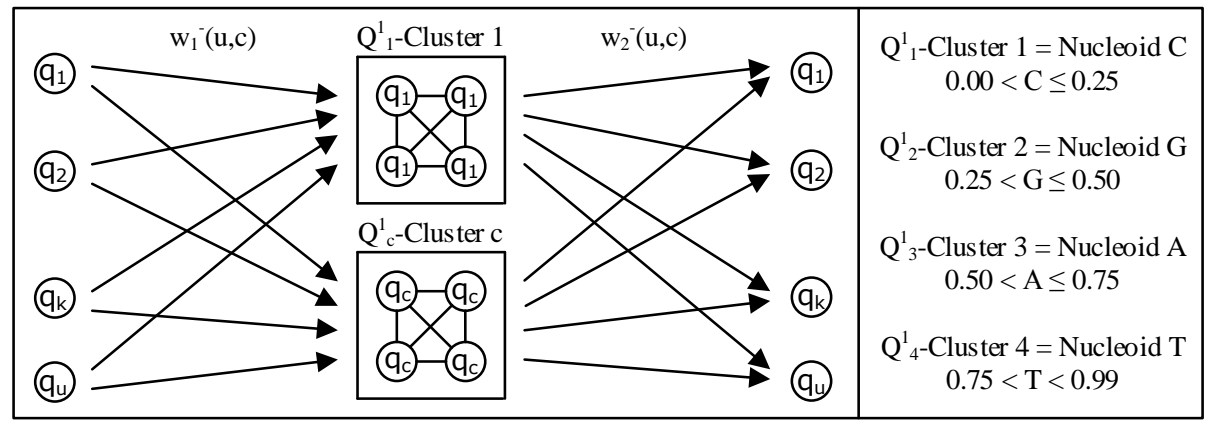

Fig. 3. Genetic Learning Algorithm

The learning algorithm is the adjustment of $\mathrm{W}_{1}$ to code the organism $\mathrm{X}$ into the four different neurons or nucleoids and then calculate $\mathrm{W}_{2}$ so that resulting decoded organism $\mathrm{Q}_{2}$ is the same as the encoded organism $\mathrm{X}$ :

$$
\min \left\|\mathrm{X}-\zeta\left(\mathrm{W}_{2} \zeta\left(\mathrm{XW}_{1}\right)\right)\right\| \text { s.t. } \mathrm{W}_{1} \geq 0
$$


Following the Extreme Learning Machine on [57]; $\mathrm{W}_{2}$ is calculated as:

$$
\mathrm{W}_{2}=\operatorname{pinv}\left(\zeta\left(\mathrm{XW}_{1}\right)\right) \mathrm{X}
$$

Where pinv is the Moore-Penrose pseudoinverse:

$$
\operatorname{pinv}(\mathrm{x})=\left(\mathrm{x}^{\mathrm{T}} \mathrm{x}\right) \mathrm{x}^{\mathrm{T}}
$$

\section{$4 \quad$ Smart Investment model}

The Smart Investment model, called "GoldAI Sachs", combines there different learnings: Reinforcement Learning, Deep Learning and Genetic Learning. "GoldAI Sachs" is formed of clusters of Intelligent Bankers that take local fast local binary decisions "Buy or Sell" on a specific assets based on Reinforcement Learning through the interactions and adaptations with the environment where the Reward is the profit made. Each Asset Banker has an associated Deep Learning cluster that memorizes asset identity such as price and reward properties. Asset bankers are dynamically clustered to different properties such as investment reward, risk or market type and managed by a Market Banker Deep Learning Management Cluster that selects the best performing Asset Bankers. Finally, a CEO Banker Deep Learning Management Cluster manages the different Bankers and takes the final investment decisions based on the Market Reward and associated Risk prioritizing markets that generate more reward at a lower Risk as every banker would do. This approach enables decisions based on shared information where Intelligent Bankers work collaborative to achieve a bigger reward.

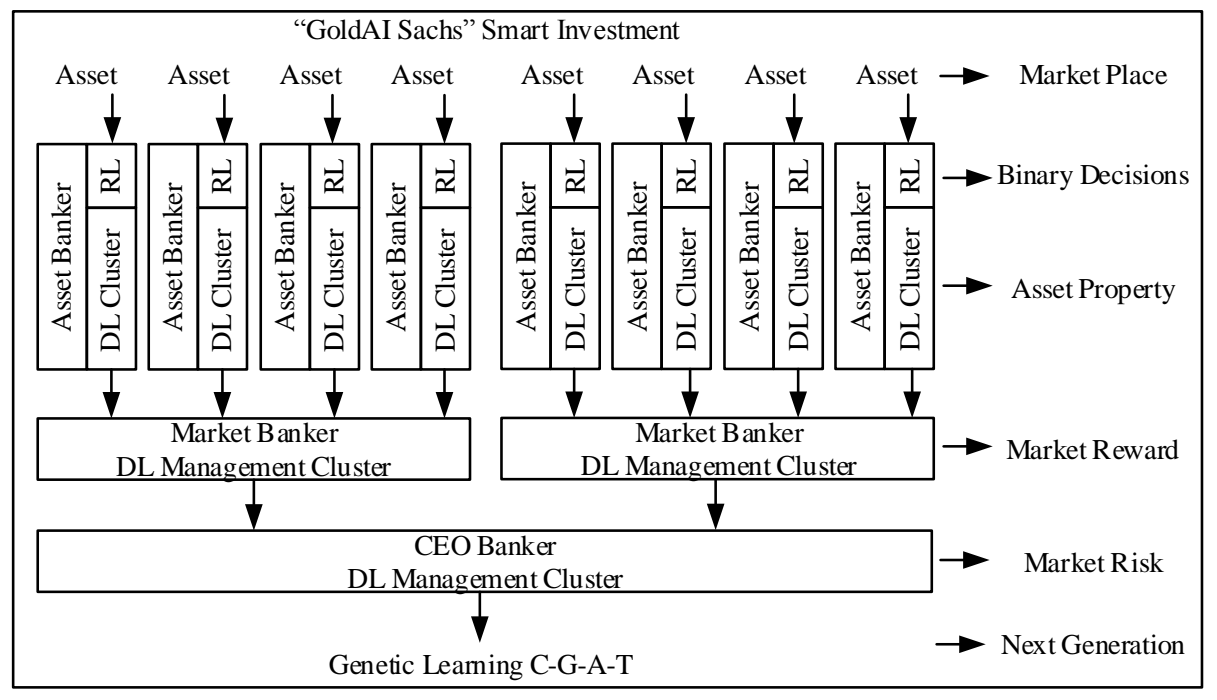

Fig. 4. "GoldAI Sachs" Smart Investment Model 


\subsection{Asset Banker Reinforcement Learning}

The Reinforcement Learning algorithm is used to take fast binary investment decisions "Buy or Sell", it is based on Cognitive Packet Network presented by Gelenbe, E. [11-15]. The Intelligent Banker is formed of two interconnected neurons " $q_{0}$ or Buy" and " $\mathrm{q}_{1}$ or Sell" where the investment decision is taken according to the neuron that has the maximum potential. The state $\mathrm{q}_{0}$ and $\mathrm{q}_{1}$ is the probability that it is excited [1115], these quantities satisfy the following system of non linear equations:

$$
\mathrm{q}_{0}=\frac{\lambda^{+}(0)}{\mathrm{r}(0)+\lambda(0)} \quad \mathrm{q}_{1}=\frac{\lambda^{+}(1)}{\mathrm{r}(1)+\lambda(1)}
$$

where:

$$
\begin{aligned}
\lambda^{+}(0) & =\mathrm{q}_{1} \mathrm{w}_{10}^{+}+\Lambda_{0} & \lambda^{+}(1) & =\mathrm{q}_{0} \mathrm{w}_{01}^{+}+\Lambda_{1} \\
\lambda^{-}(0) & =\mathrm{q}_{1} \mathrm{w}_{10}^{-}+\lambda_{0} & \lambda^{-}(1) & =\mathrm{q}_{0} \mathrm{w}_{01}^{-}+\lambda_{1} \\
\mathrm{r}(0) & =\mathrm{w}_{01}^{+}+\mathrm{w}_{01}^{-} & \mathrm{r}(1) & =\mathrm{w}_{10}^{+}+\mathrm{w}_{10}^{-}
\end{aligned}
$$

On the above equations, $\mathrm{w}_{\mathrm{ij}}^{+}$is the rate at which neuron $\mathrm{i}$ transmits excitation spikes to neuron $\mathrm{j}$ and $\mathrm{w}_{\mathrm{ij}}$ is the rate at which neuron $\mathrm{i}$ transmits inhibitory spikes to neuron $\mathrm{j}$ in both situations when neuron $i$ is excited. $\Lambda_{i}$ and $\lambda_{i}$ are the rates of external excitatory and inhibitory signals respectively.

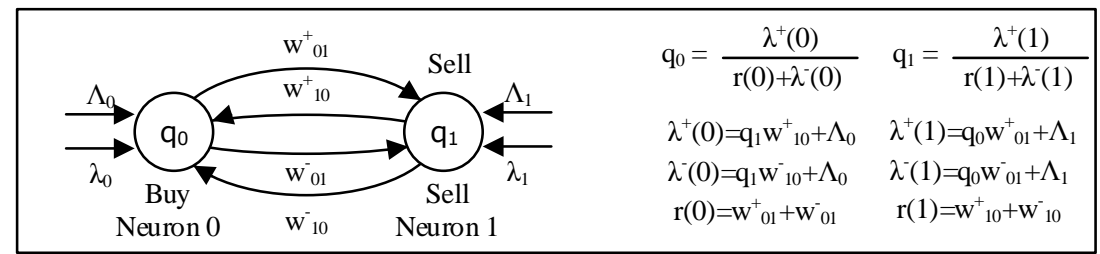

Fig. 5. Asset Banker Reinforcement Learning

The Reward $\mathrm{R}$ is based on the economic profit that the Asset Bankers achieve with the decisions they make, successive measured values of the $R$ are denoted by $R_{1}, 1=1,2 \ldots$. these are used to compute the Predicted Reward:

$$
\mathrm{PR}_{1}=\alpha \mathrm{PR}_{\mathrm{l}-1}+(1-\alpha) \mathrm{R}_{1}
$$

where $\alpha$ represents the investment reward memory.

If the observed measured Reward is greater than the associated Predicted Reward; Reinforcement Learning rewards the decision taken by increasing the network weight that point to it, otherwise; it penalises it. 


\section{$5 \quad$ Experimental results}

"GoldAI Sachs" is evaluated with eight different assets to assess the adaptability and performance of our proposed Smart Investment solution for eleven days. The assets are split into the Bond Market with low risk and slow reward and the Derivative Market with high risk and fast reward. Experiments are carried with very reduced memory $\alpha=0.1$ where the Reinforcement Learning is first initialized with a Buy Decision.

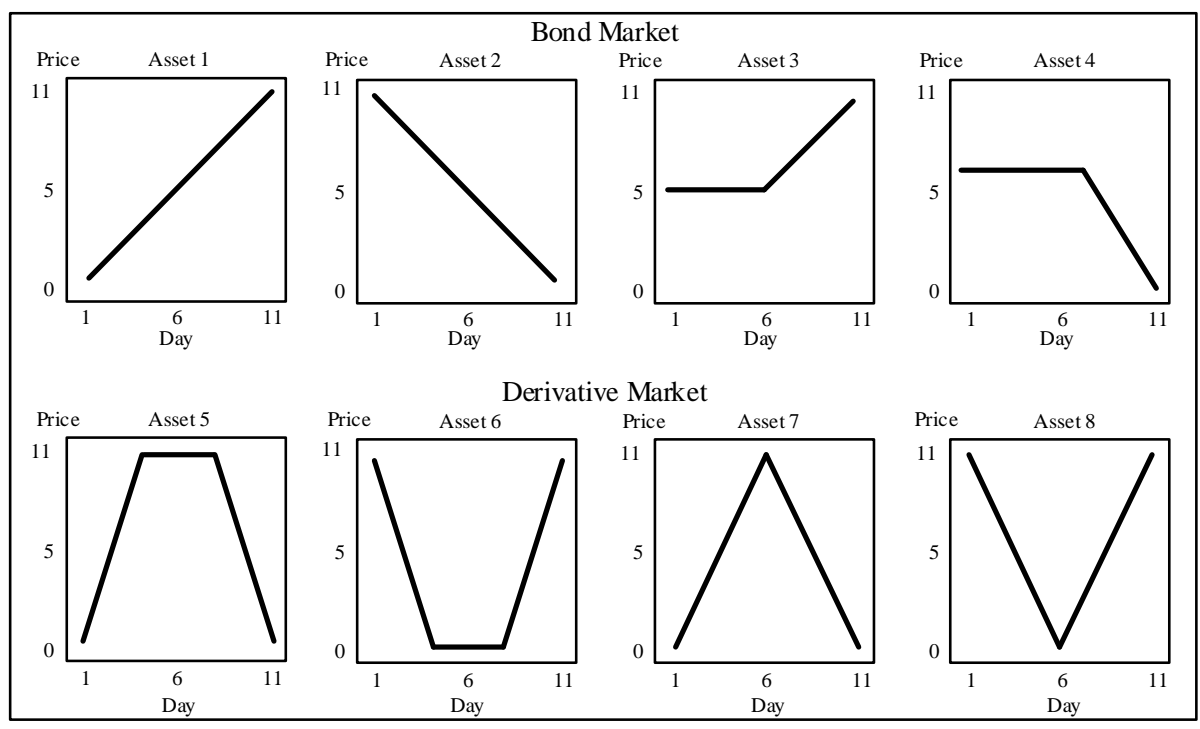

Fig. 6. "GoldAI Sachs" Smart Investment Model assets

\subsection{Asset Banker Reinforcement Learning Validation}

Table 1 represents the Profit that each Asset Banker makes when buying or selling 100 Assets for 11 days with the Maximum Profit, the number of winning decisions against the losing ones and the number of buy decisions against the sell.

Table 1. Asset Banker Reinforcement Learning Validation

\begin{tabular}{ccccccc}
\hline Asset & Profit & Maximum Profit & Win & Loss & Buy & Sell \\
\hline $\mathbf{1}$ & 1000 & 1000 & 10 & 0 & 10 & 0 \\
\hline $\mathbf{2}$ & 800 & 1000 & 9 & 1 & 1 & 9 \\
\hline $\mathbf{3}$ & 600 & 600 & 6 & 0 & 10 & 0 \\
\hline $\mathbf{4}$ & 300 & 500 & 4 & 1 & 6 & 4 \\
\hline $\mathbf{5}$ & 2000 & 2000 & 8 & 0 & 4 & 6 \\
\hline
\end{tabular}




\begin{tabular}{ccccccc}
\hline $\mathbf{6}$ & 1200 & 2000 & 6 & 2 & 4 & 6 \\
\hline $\mathbf{7}$ & 1600 & 2000 & 9 & 1 & 6 & 4 \\
\hline $\mathbf{8}$ & 800 & 2000 & 7 & 3 & 4 & 6 \\
\hline
\end{tabular}

The Profit made in assets that start downwards such as Asset 2, Asset 4, Asset 6 and Asset 8 is worse than the upwards ones because the Asset Bankers are initialized with a buy decision. The Reinforcement Learning Algorithm adapts very quickly to variable asset prices.

\subsection{Market Banker Deep Learning Management Cluster Validation}

The profits the Market Bankers can make are shown in Table 2 and Table 3. The Market Bankers take market decisions rather than individual asset decisions form the Asset Bankers. Market Bankers invests 400 assets which is the combination of the four Asset Bankers purchasing power.

Table 2. Bond Market Banker Profits

\begin{tabular}{ccccccc}
\hline Day & $\begin{array}{c}\text { Total Asset } \\
\text { Banker }\end{array}$ & Bond Market & I & $\begin{array}{c}\text { Maximum } \\
\text { Asset }\end{array}$ & $\begin{array}{c}\text { Maximum } \\
\text { Market }\end{array}$ & I \\
\hline $\mathbf{2}$ & 0 & 400 & $400.00 \%$ & 200 & 400 & $100.00 \%$ \\
\hline $\mathbf{3}$ & 200 & 400 & $100.00 \%$ & 200 & 400 & $100.00 \%$ \\
\hline $\mathbf{4}$ & 200 & 400 & $100.00 \%$ & 200 & 400 & $100.00 \%$ \\
\hline $\mathbf{5}$ & 200 & 400 & $100.00 \%$ & 200 & 400 & $100.00 \%$ \\
\hline $\mathbf{6}$ & 300 & 400 & $33.33 \%$ & 300 & 400 & $33.33 \%$ \\
\hline $\mathbf{7}$ & 200 & 400 & $100.00 \%$ & 400 & 400 & $0.00 \%$ \\
\hline $\mathbf{8}$ & 400 & 400 & $0.00 \%$ & 400 & 400 & $0.00 \%$ \\
\hline $\mathbf{1 0}$ & 400 & 400 & $0.00 \%$ & 400 & 400 & $0.00 \%$ \\
\hline $\mathbf{1 1}$ & 400 & 400 & $0.00 \%$ & 400 & 400 & $0.00 \%$ \\
\hline Total & 2700 & 400 & $0.00 \%$ & 400 & 400 & $0.00 \%$ \\
\hline
\end{tabular}

Table 3. Derivative Market Banker Profits

\begin{tabular}{ccccccc}
\hline Day & $\begin{array}{c}\text { Total Asset } \\
\text { Banker }\end{array}$ & $\begin{array}{c}\text { Derivative } \\
\text { Market }\end{array}$ & I & $\begin{array}{c}\text { Maximum } \\
\text { Asset }\end{array}$ & $\begin{array}{c}\text { Maximum } \\
\text { Market }\end{array}$ & I \\
\hline $\mathbf{2}$ & 0 & 800.0 & $400.00 \%$ & 800 & 800.0 & $400.00 \%$ \\
\hline $\mathbf{3}$ & 1000 & 1200 & $20.00 \%$ & 1000 & 1200 & $20.00 \%$ \\
\hline
\end{tabular}




\begin{tabular}{ccccccc}
\hline $\mathbf{4}$ & 1000 & 1200 & $20.00 \%$ & 1000 & 1200 & $20.00 \%$ \\
\hline $\mathbf{5}$ & 800 & 800 & $0.00 \%$ & 800 & 800 & $0.00 \%$ \\
\hline $\mathbf{6}$ & 400 & 0 & $-100.00 \%$ & 400 & 0 & $-100.00 \%$ \\
\hline $\mathbf{7}$ & -400 & -800 & $100.00 \%$ & 400 & 800 & $100.00 \%$ \\
\hline $\mathbf{8}$ & 0 & 800 & $800 \%$ & 800 & 800 & $0.00 \%$ \\
\hline $\mathbf{9}$ & 1000 & 1200 & $20.00 \%$ & 1000 & 1200 & $20.00 \%$ \\
\hline $\mathbf{1 0}$ & 1000 & 1200 & $20.00 \%$ & 1000 & 1200 & $20.00 \%$ \\
\hline $\mathbf{1 1}$ & 800 & 800 & $0.00 \%$ & 800 & 800 & $0.00 \%$ \\
\hline Total & 5600 & 7200 & $28.57 \%$ & 8000 & 8800 & $10.00 \%$ \\
\hline
\end{tabular}

\subsection{CEO Banker Deep Learning Management Cluster Validation}

Table 4 represents the CEO Banker, "AI Morgan" profits at different Risks ratios with a total of investment of 800 assets. A risk value $\beta=0.2$ represents 640 assets in the Bond Market and 160 is the Derivative Market whereas a risk value $\beta=0.8$ is 160 assets in the Bond Market and 640 in the Derivative Market respectively.

Table 4. CEO Banker Profits

\begin{tabular}{|c|c|c|c|c|c|c|c|c|c|c|}
\hline \multirow{2}{*}{ Day } & \multicolumn{3}{|c|}{ Risk $\boldsymbol{\beta}=0.2$} & \multicolumn{3}{|c|}{ Risk $\beta=0.5$} & \multicolumn{3}{|c|}{ Risk $\beta=0.8$} & \multirow{2}{*}{$\begin{array}{l}\text { Max } \\
\text { Profit }\end{array}$} \\
\hline & B & D & Total & B & D & Total & B & D & Total & \\
\hline 2 & 640 & 320 & 960 & 400 & 800 & 1200 & 160 & 1280 & 1440 & 1440 \\
\hline 3 & 640 & 480 & 1120 & 400 & 1200 & 1600 & 160 & 1920 & 2080 & 2080 \\
\hline 4 & 640 & 480 & 1120 & 400 & 1200 & 1600 & 160 & 1920 & 2080 & 2080 \\
\hline 5 & 640 & 320 & 960 & 400 & 800 & 2800 & 160 & 1280 & 1440 & 1440 \\
\hline 6 & 640 & 0 & 640 & 400 & 0 & 400 & 160 & 0 & 160 & 640 \\
\hline 7 & 640 & -320 & 320 & 400 & -800 & -400 & 160 & -1280 & -1120 & 320 \\
\hline 8 & 640 & 320 & 960 & 400 & 800 & 1200 & 160 & 1280 & 1440 & 1440 \\
\hline 9 & 640 & 480 & 1120 & 400 & 1200 & 1600 & 160 & 1920 & 2080 & 2080 \\
\hline 10 & 640 & 480 & 1120 & 400 & 1200 & 1600 & 160 & 1920 & 2080 & 2080 \\
\hline 11 & 640 & 640 & 1280 & 400 & 800 & 1200 & 160 & 1280 & 1440 & 1440 \\
\hline Total & 6400 & 2880 & 9280 & 4000 & 7200 & 11200 & 1600 & 11520 & 13120 & 15040 \\
\hline
\end{tabular}




\subsection{Genetic Algorithm Validation}

The Genetic Algorithm validation for the four different Nucleoids (C,G,A,T) during the 11 different days is shown in Table 5 with the Genetic Algorithm Error.

Table 5. Genetic Algorithm Validation

\begin{tabular}{cccccc}
\hline Day & Error & Nucleoid-C & Nucleoid-G & Nucleoid-A & Nucleoid-T \\
\hline $\mathbf{2}$ & $3.05 * 10 \mathrm{E}-31$ & 0.2048 & 0.3893 & 0.6295 & 0.9268 \\
\hline $\mathbf{3}$ & $5.85 * 10 \mathrm{E}-31$ & 0.2026 & 0.3861 & 0.6263 & 0.9259 \\
\hline $\mathbf{4}$ & $6.78 * 10 \mathrm{E}-32$ & 0.2025 & 0.3859 & 0.6262 & 0.9259 \\
\hline $\mathbf{5}$ & $1.17 * 10 \mathrm{E}-31$ & 0.2029 & 0.3865 & 0.6267 & 0.9260 \\
\hline $\mathbf{6}$ & $4.44 * 10 \mathrm{E}-31$ & 0.2033 & 0.3870 & 0.6272 & 0.9262 \\
\hline $\mathbf{7}$ & $1.29 * 10 \mathrm{E}-31$ & 0.2049 & 0.3894 & 0.6296 & 0.9269 \\
\hline $\mathbf{8}$ & $3.61 * 10 \mathrm{E}-31$ & 0.2031 & 0.3868 & 0.6271 & 0.9261 \\
\hline $\mathbf{9}$ & $2.96 * 10 \mathrm{E}-31$ & 0.2021 & 0.3852 & 0.6255 & 0.9257 \\
\hline $\mathbf{1 0}$ & $6.90 * 10 \mathrm{E}-31$ & 0.2020 & 0.3851 & 0.6254 & 0.9256 \\
\hline $\mathbf{1 1}$ & $1.36 * 10 \mathrm{E}-31$ & 0.2023 & 0.3856 & 0.6259 & 0.9258 \\
\hline
\end{tabular}

\section{Conclusions}

This paper has presented a new learning Genetic Algorithm based on the Genome where the information is transmitted in the network weights rather than the neurons. The algorithm has been incremented in an Smart Investment model that simulates the human brain with reinforcement learning for fast decisions, deep learning to memorize properties to create asset identity, deep learning management clusters to make global decisions and genetic to transmit learning into future generations .

In the Smart Investor Model, "GoldAI Sachs" Asset Banker Reinforcement Learning Algorithm takes the right investment decisions; with great adaptability to asset price changes whereas Asset Banker Deep Learning provides asset properties and identity. Market Bankers success to increase the profit by selecting the best performing Asset Bankers and the CEO Banker, "AI Morgan" increases the profits considering the associated market risks, prioritizing low risk investment decision at equal profit. Genetic learning algorithm has a minimum error and it exactly codes and encodes the CEO Banker, "AI Morgan".

Future work will validate our model in a Fintech cryptocurrency environment with real market values. In addition the relevance of memory in investment with its optimum value will be analyzed. 


\section{References}

1. M. Kirschner, J. Gerhart. The Plausibility of Life Resolving Darwin's Dilemma. Yale University Press. (2005)

2. M. Parter, N. Kashtan, U. Alon. Facilitated Variation: How Evolution Learns from Past Environments To Generalize to New Environments. Department of Molecular Cell Biology, Weizmann Institute of Science.

3. G. Hinton, S. Nowlan. How learning can guide evolution. Adaptive individuals in evolving populations. (1996), 447-454.

4. M. Pellegrini, E. Marcotte, M. Thompson, D. Eisenberg, T. Yeates. Assigning protein functions by comparative genome analysis: Protein phylogenetic profiles. Proceedings of the National Academia of Sciences of the United States of America. 96, (1999), 42854288.

5. M. Suzuki. A framework for the DNA protein recognition code of the probe helix in transcription factors: the chemical and stereo chemical rules. 2, 4, (1994), $317-326$.

6. D. Smith, E. Bullmore. Small-World Brain Networks. The Neuroscientist. 12, (2007), 51223.

7. O. Sporns, D. Chialvo, M. Kaiser, C. Hilgetag. Organization, development and function of complex brain networks. Trends in Cognitive Sciences. 8,9, (2004), 418-425.

8. M. Leshno, Y. Spector: Neural network prediction analysis: The bankruptcy case. Neurocomputing. 10, 2, (1996), 125-147.

9. W. Chen, Y. Du. Using neural networks and data mining techniques for the financial distress prediction model. Expert Systems with Applications. 36, (2009), 4075-4086.

10. Y. Kara, M. Acar, Ö. Kaan. Predicting direction of stock price index movement using artificial neural networks and support vector machines: The sample of the Istanbul Stock Exchange. Expert Systems with Applications. 38, (2011), 5311-5319.

11. E. Guresen, Gulgun Kayakutlu, Tugrul U. Daim. Using artificial neural network models in stock market index prediction. Expert Systems with Applications 38 (2011) 10389-10397

12. G. Zhang, M. Hu, B. Patuwo, D. Indro. Artificial neural networks in bankruptcy prediction: General framework and cross-validation analysis. European Journal of Operational Research. 116, (1999), 16-32.

13. K. Kohara, T. Ishikawa, Y. Fukuhara, Y. Nakamura. Stock Price Prediction Using Prior Knowledge and Neural Networks. Intelligent Systems in Accounting, Finance and Management. 6, (1997), 11-22.

14. A. Sheta, S. Ahmed, H. Faris. A Comparison between Regression, Artificial Neural Networks and Support Vector Machines for Predicting Stock Market Index. International Journal of Advanced Research in Artificial Intelligence. 4, 7, (2015), 55-63.

15. T. Khuat, M. Le. An Application of Artificial Neural Networks and Fuzzy Logic on the Stock Price Prediction Problem. International Journal on Informatics Visualization. 1, 2 (2017), 40-49.

16. M. Naeini, H. Taremian, H. Hashemi. Stock market value prediction using neural networks. International Conference on Computer Information Systems and Industrial Management Applications. (2010), 132-136.

17. G. Iuhasz, M. Tirea, V. Negru. Neural Network Predictions of Stock Price Fluctuations. International Symposium on Symbolic and Numeric Algorithms for Scientific Computing. (2012), 505-512.

18. A. Nicholas, A. Zapranis, G. Francis. Stock performance modeling using neural networks: A comparative study with regression models. Neural Networks. 7, 2, (1994), 375-388. 
19. A. Bahrammirzaee. A comparative survey of artificial intelligence applications in finance: artificial neural networks, expert system and hybrid intelligent systems. Neural Computation \& Applications. 19, (2010), 1165-1195.

20. J. Coakley, C. Brown. Artificial Neural Networks in Accounting and Finance: Modeling Issues. International Journal of Intelligent Systems in Accounting, Finance \& Management. (2000), 119-144.

21. A. Fadlalla, C. Lin. An Analysis of the Applications of Neural Networks in Finance. Interfaces. 31, 4, (2001), 112-122.

22. W. Huang, K. Lai, Y. Nakamori, S. Wang, L. Yu. Neural Networks in Finance and Economics Forecasting. International Journal of Information Technology and Decision Making. 6, 1, (2007), 113-140.

23. Y. Li, W. Jiang, L. Yang, T. Wu. On neural networks and learning systems for business computing. Neurocomputing. 275, (2018), 1150-1159.

24. V. Duarte. Macro, Finance, and Macro Finance: Solving Nonlinear Models in Continuous Time with Machine Learning. Massachusetts Institute of Technology, Sloan School of Management. (2017), 1-27.

25. J. Stefani, O. Caelen, D. Hattab, G. Bontempi. Machine Learning for Multi-step Ahead Forecasting of Volatility Proxies. Workshop on Mining Data for financial applications. (2017), 1-12.

26. T. Fischer, C. Krauss: Deep learning with long short-term memory networks for financial market predictions. FAU discussion Papers in Economics. 11, (2017) , 1-32.

27. A. Hasan, O. Kalıpsız, S. Akyokuş. Predicting financial market in big data: Deep learning. International Conference on Computer Science and Engineering. (2017), 510-515.

28. J. Arifovic . Genetic algorithms and inflationary economies. Journal of Monetary Economics. 36, (1995), $219-243$.

29. K. Kim, I. Han. Genetic algorithms approach to feature discretization in artificial neural networks for the prediction of stock price index. Expert Systems with Applications. 19, (2000), 125-132.

30. W. Ticona, K. Figueiredo, M. Vellasco. Hybrid model based on genetic algorithms and neural networks to forecast tax collection: Application using endogenous and exogenous variables International Conference on Electronics, Electrical Engineering and Computing. (2017), 1-4.

31. D. Hossain, G. Capi. Genetic Algorithm Based Deep Learning Parameters Tuning for Robot Object Recognition and Grasping. International Scholarly and Scientific Research \& Innovation. 11, 3, (2017), 629-633.

32. S. Tirumala. Implementation of Evolutionary Algorithms for Deep Architectures. Artificial Intelligence and Cognition. (2014), 164-171.

33. O. David, I. Greental. Genetic algorithms for evolving deep neural networks. ACM Genetic and Evolutionary Computation Conference. (2014), 1451-1452.

34. E. Gelenbe. Random Neural Networks with Negative and Positive Signals and Product Form Solution. Neural Computation. 1, (1989), 502-510.

35. E. Gelenbe. Learning in the Recurrent Random Neural Network. Neural Computation. 5, (1993), 154-164.

36. E. Gelenbe. G-Networks with Triggered Customer Movement. Journal of Applied Probability. 30, (1993), 742-748.

37. E. Gelenbe "A class of genetic algorithms with analytical solution", Robotics and Autonomous Systems, Volume 22, Issue 1, 10 November 1997, Pages 59-64. 
38. E. Gelenbe "Steady-state solution of probabilistic gene regulatory networks", Physical Review E, 76(1), 031903 (2007), also in Virtual Journal of Biological Physics Research, September $15,2007$.

39. E. Gelenbe, P. Liu and J. Laine "Genetic algorithms for route discovery", IEEE Trans. Systems, Man and Cybernetics B, 36 (6): 1247-1254, 2006.

40. E. Gelenbe "Dealing with software viruses: a biological paradigm", Information Security Tech- nical Reports 12: 242-250, Elsevier Science, 2007.

41. E. Gelenbe "Network of interacting synthetic molecules in equilibrium", Proc. Royal Society A (Mathematical and Physical Sciences) 464:2219-2228, April 2008.

42. H. Kim and E. Gelenbe "Anomaly detection in gene expression via stochastic models of gene regulatory networks”, BMC Genomics 10(Suppl 3):S26, 2009, doi: 10.1186/14712164-10-S3-S26

43. H. Kim and E. Gelenbe "Stochastic gene expression modeling with hill function for switch-like gene responses" IEEE/ACM Transactions on Computational Biology and Bioinformatics 9 (4): 973-979, 2012, ISSN: 1545-5963, doi: 10.1109/TCBB.2011.153.

44. H.Kim and E.Gelenbe"Reconstruction of Large-scale Gene Regulatory Networks using Bayesian Model Averaging", IEEE Transactions on NanoBioscience 11 (3): 259-265, 2012, doi: 10.1109/TNB.2012.221

45. E. Gelenbe "Natural Computation", Computer Journal 55(7): 848-851, 2012.

46. Haseong Kim, Taesung Park and Erol Gelenbe "Identifying disease candidate genes via large- scale gene network analysis' IJDMB 10(2): 175-188, 2014.

47. E. Gelenbe, Y. Yin. Deep learning with random neural networks. International Joint Conference on Neural Networks. (2016), 1633-1638.

48. Y. Yin, E. Gelenbe. Deep Learning in Multi-Layer Architectures of Dense Nuclei. CoRR abs/1609.07160, (2016), 1-10.

49. Y. Yin, E. Gelenbe. Single-cell based random neural network for deep learning. International Joint Conference on Neural Networks. (2017), 86-93.

50. E. Gelenbe: G-Networks: A Unifying Model for Neural Nets and Queueing Networks. Modelling Analysis and Simulation of Computer and Telecommunications Systems. (1993), 3-8.

51. J. Fourneau, E. Gelenbe, R. Suros. G-Networks with Multiple Class Negative and Positive Customers. Modelling Analysis and Simulation of Computer and Telecommunications Systems. (1994), 30-34.

52. E. Gelenbe, S. Timotheou. Random Neural Networks with Synchronized Interactions. Neural Computation. 20-9, (2008), 2308-2324.

53. W. Serrano, E Gelenbe. An Intelligent Internet Search Assistant Based on the Random Neural Network. Artificial Intelligence Applications and Innovations. (2016), 141-153.

54. W. Serrano. A Big Data Intelligent Search Assistant Based on the Random Neural Network. International Neural Network Society Conference on Big Data. (2016), 254-261.

55. W. Serrano, E. Gelenbe. Intelligent Search with Deep Learning Clusters. Intelligent Systems Conference. (2017), 254-267.

56. W. Serrano, E. Gelenbe. The Deep Learning Random Neural Network with a Management Cluster. International Conference on Intelligent Decision Technologies. (2017) 185-195.

57. L. Kasun, H. Zhou, G. Huang. Representational learning with extreme learning machine for big data. IEEE Intelligent Systems. 28, 6, (2013), 31-34. 
Appendix: Smart Investment model - Neural Schematic

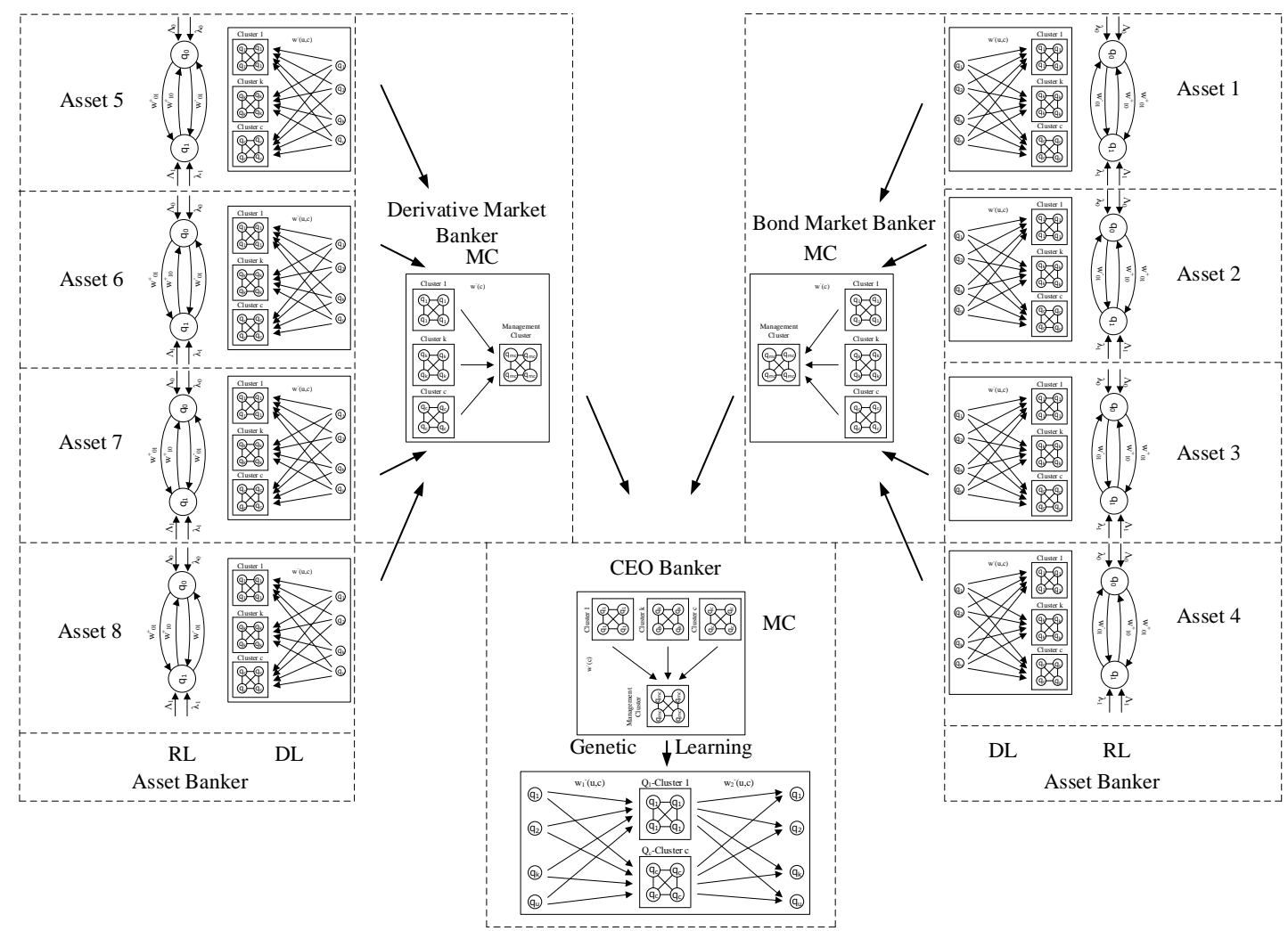

